\title{
Acute and Persistence Effects of Oil of Hippophae rhamnoides and Calendula officinalis on Sitophilus granarius (Coleoptera: Curculionidae) in Stored Maize
}

\author{
S. KESZTHELYI*, R. HOFFMANN, Zs. PÓNYA and F. PÁL-FÁM \\ Department of Plant Production and Protection, Faculty of Agricultural and Environmental Sciences, Kaposvár \\ University, H-7400 Kaposvár, S. Guba út 40, Hungary
}

(Received: 20 March 2017; accepted: 24 May 2017)

\begin{abstract}
Herbal oil vapours from Hippophae rhamnoides L. (Elaeagnaceae), and Calendula officinalis L. (Asteraceae) were tested for their toxicity against the adults of Sitophilus granarius L.. According to our hypothesis the mentioned oils can become potential bioagents against stored product pests. The results revealed that both studied essential oils exerted strongly toxic effect on $S$. granarius, but $C$. officinalis triggered higher mortality. The efficacy $(94.62 \pm 2.63 \%)$ was reached after a 48 -h exposure to $H$. rhamnoides oil at $2 \mathrm{ml} \mathrm{kg}^{-1}$ while the application of $2 \mathrm{ml} \mathrm{kg}^{-1}$ of $C$. officinalis oil for $24 \mathrm{~h}$ produced $98.94 \pm 1.00 \%$ mortality rate. Insect mortality was hyperbolically-featured, and increased with the duration of the exposure to the examined oils. Mortality was $100 \%$ at $5 \mathrm{ml} \mathrm{kg}{ }^{-1}$ of $H$. rhamnoides after 24-h duration of its application, while with $C$. officinalis the same value could be reached after a 12-h exposure to the oil. The progeny pronouncedly recovered from the treatment of both essential oils applied.
\end{abstract}

Keywords: herbal oil, acute effect, persistence effect, Hippophae rhamnoides L., Calendula officinalis L., Sitophilus granarius L.

Granary weevil Sitophilus granarius L. is a typical cosmopolitan pest. It can cause significant damage to stored grains, and can drastically decrease yields (Fava and Burlando, 1995). Damaged grain has reduced nutritional- and market value, low percentage germination, and reduced weight (Stejskal and Kucerova, 1996), which, coupled with the need of reducing the use of synthetic chemicals in agricultural production, calls for environmentally friendly, economical and effective methods for diminishing damage caused by $S$. granarius in stored grain stocks.

Insecticides are the most commonly used protectants in stored grain against stored-product pests in many European countries. They are applied directly to the product and provide protection as long as the insecticidal effect persists. However, these pesticides have negative side-effects in case as they can be toxic to mammals since the residues can accumulate in the treated products. Furthermore, many pest species can become resistant against the protectants (Arthur, 1996).

* Corresponding author; e-mail: ostrinia@gmail.com 
In this regard plant-derived essential oils may prove to be viable alternatives due to their broad-spectrum pest-control properties. They have potential applicability as fumigants against stored product insects (Sarac and Tunc, 1995; Tripathi et al., 1999; Tunc et al., 2000). Additionally, their repellent, growth-inhibiting and reproduction-retarding effects on storage pests have been demonstrated ( $\mathrm{Su}, 1991)$. Many species of oleaginous plant families possess insecticidal and repellent effects against $S$. granarius, the most important of which are the Lamiaceae family, but several species of Apiaceae, Anacardiaceae, Asteraceae and Myrtaceae may also contain several important insecticidal compounds.

Here we report the findings of our investigation conducted in order to determine the efficacy of different essential oils when applied to stored grain stocks. Treatment with the essential oil of Rosmarinus officinalis L., resulted in more than 50\% mortality in the adults of granary weevil at $35^{\circ} \mathrm{C}(89 \%)$ and $40{ }^{\circ} \mathrm{C}(99 \%)$ (Yildirim et al., 2011; Laznik et al., 2012). A satisfactory efficacy of the other essential oils, Lavandula angustifolia Mill. (90\%), Mentha balsamea Willd. (97\%) and Salvia officinalis L. (94\%), was attained only at the highest temperature applied (Laznik et al., 2012). Origanum acutidens Hand.-Mazz oil showed $68.3 \%$ mortality (Kordali et al., 2008). One hundred percent mortality was achieved by Calmasur et al. (2006) with $2 \mu \mathrm{l} / \mathrm{l}$ air doses of the essential oils of Achillea biebersteinii Afan. and A. wilhelmsii Koch against S. granarius. Kordali et al. (2006) concluded that essential oils and their major components (1,8-cineole and terpinen-4-ol) of three Artemisia species are potential control agents against this pest. Concerning their potential use in biological control of pests jeopardising stored grain-health, Pistacia species were investigated by Aslan et al. (2004). Although desirable insecticidal effects against S. granarius were achieved with essential oils of Pistacia lentiscus L., P. terebinthus L. and $P$. vera L., the oil of $P$. vera was found to be the most effective. Complete kill could be achieved for the essential oil of $P$. vera at 4 and $8 \mu \mathrm{l} / \mathrm{l}$ air for $96 \mathrm{~h}$.

Further, Hyptis suaveolens L. essential oil and its major constituents were evaluated for their repellent activity against adults of the granary weevil S. granarius in Petri dish-tests and in pitfall bioassays (Benelli et al., 2012). The repellent activity of Ocimum species was proven by Obeng-Ofori and Reichmuth (1997), Obeng-Ofori et al. (1997). Although the antibacterial effect of the essential oils of Hippophae rhamnoides L. (Chauhan et al., 2007; Michel et al., 2012) and Calendula officinalis L. (Chakraborthy, 2008; Efstratiou et al., 2012) have been explored, their insecticidal potency is not known in detail.

The aim of this study was to contribute to endeavours made in this direction by assessment of the toxicity of $H$. rhamnoides, and $C$. officinalis oils so that the control of $S$. granarius in stored grains via biological means would eventually become possible. The examined essential oils were tested on oil-impregnated paper and no data are presented on the effect of oil-grain mixtures. This techniques would qualify as "organic" and are in line with principles and practices of organic farming standards. Therefore, our results may give impetus to efforts made in order to explore environmentally-friendly means in combating this serious pest. 


\section{Materials and Methods}

Untreated, clean and entirely infestation-free maize grains were used for experimentation. The maize grain samples were treated with two types of herbal plant oils, $H$. rhamnoides and $C$. officinalis. The herbal oils of $H$. rhamnoides and $C$. officinalis were purchased from HBHM Global Ltd. (Kaposvár, Hungary) in $50 \mathrm{ml}$ bottles. The herbal oils used were $100 \%$ natural essences of medicinal plants. The oils were stored at $5{ }^{\circ} \mathrm{C}$ until use. Individuals of adult $S$. granarius were obtained from stocks maintained at Pest Rearing Laboratory of the Hungarian Government Office of Somogy County, Department of Plant Protection and Soil Conservation.

The applied concentrations besides the untreated (control) samples were as follows: $0.5 \mathrm{ml} \mathrm{kg}-1,1 \mathrm{ml} \mathrm{kg}{ }^{-1}, 2 \mathrm{ml} \mathrm{kg}^{-1}$ and $5 \mathrm{ml} \mathrm{kg}$ of grain. The consistent distribution of oils dripped on the surface of the grain was ensured by thorough mixing for 5 minutes (Laznik et al., 2012).

To evaluate the acute toxicity on adults for each dose, five samples of $200 \mathrm{~g}$ maize grain were treated. Each sample was placed in a small glass vial, 20 healthy $S$. granarius adults of mixed sexes were added, after which the vials were covered with well-ventilated textiles and placed in incubators at $26 \pm 2{ }^{\circ} \mathrm{C}$ and $60 \pm 7 \% \mathrm{rh}$. Dead adults were counted after 12, 24, 48 and $72 \mathrm{~h}$.

To assess persistence effect [i.e. long-term consequences of the treatment (Ilboudo et al., 2010; Laznik et al., 2012)], all conditions were the same as in acute toxicity-experimentation only the covering materials of vials and exposure times were different. One of the groups was covered with ventilated textiles (VT), whereas the others with perforated nylon film (PN). Dead adults were counted after 7, 14 and $21 \mathrm{~d}$.

For determining the effect of plant oils on progeny, following the 21-day count, the adult insects (both dead and alive) were removed from both parts of each sample, after which the vials were returned to the incubator for another $45 \mathrm{~d}$. After this period, the emerged $S$. granarius adults were counted, classified as dead or alive and removed from the vials. These adults were observed for survival and progeny production as an indication of reproductive ability.

Mortality was evaluated as a function of both 1st/time elapsed after exposure and 2nd/dose rate. Mortality counts were corrected by using Abbott's (1925) formula. The data were analysed using the one-way ANOVA in SPSS 11.5 software, with weevil mortality as the response variable and 1 st/time after exposure and $2 \mathrm{nd} /$ dose rate as the main effects. Means were separated by using the Tukey (HSD) test, at $\mathrm{P} \leq 0.05$. The numbers of progeny were also examined statistically by the one-way ANOVA software (Tukey test, $\mathrm{P} \leq 0.05$ ). The effect of the covering materials (ventilated textile compared to perforated nylon film) was analyzed by Student $t$-probe $(\mathrm{P} \leq 0.05)$.

\section{Results}

Mortality of $S$. granarius adults was significantly affected by the exposure time to both herbal oils $(H$. rhamnoides: $\mathrm{df}=6, F=22.580, P=0.000 ; C$. officinalis: $\mathrm{df}=6$, 


\section{Table 1}

One-way ANOVA parameters for main effects (applied doses) for mortality levels of Sitophilus granarius adults within acute exposure times (12-72 h) [covered by ventilated textile (VT)]

\begin{tabular}{|c|c|c|c|c|}
\hline & $12 \mathrm{~h}$ & $24 \mathrm{~h}$ & $48 \mathrm{~h}$ & $72 \mathrm{~h}$ \\
\hline \multicolumn{5}{|c|}{ Hippophae rhamnoides } \\
\hline $\mathrm{df}$ & \multicolumn{4}{|c|}{ between groups $=3$; within groups $=16 ;$ total $=19$} \\
\hline$F$ & 44.742 & 32.007 & 16.422 & 13.387 \\
\hline$P$ & \multicolumn{4}{|c|}{0.000} \\
\hline \multicolumn{5}{|c|}{ Calendula officinalis } \\
\hline df & \multicolumn{4}{|c|}{ between groups $=3$; within groups $=16$; total $=19$} \\
\hline$F$ & 27.265 & 29.592 & 20.928 & 16.622 \\
\hline$P$ & \multicolumn{4}{|c|}{0.000} \\
\hline
\end{tabular}

Table 2

One-way ANOVA parameters for main effects (applied doses) for mortality levels of Sitophilus granarius adults within persistence exposure times (7-21 d)[covered by ventilated textile (VT) and perforated nylon (PN)]

\begin{tabular}{|c|c|c|c|c|c|c|}
\hline & \multicolumn{2}{|c|}{$7 \mathrm{~d}$} & \multicolumn{2}{|c|}{$14 \mathrm{~d}$} & \multicolumn{2}{|c|}{$21 \mathrm{~d}$} \\
\hline & VT & $\mathrm{PN}$ & VT & $\mathrm{PN}$ & VT & $\mathrm{PN}$ \\
\hline \multicolumn{7}{|c|}{ Hippophae rhamnoides } \\
\hline df & \multicolumn{6}{|c|}{ between groups $=3$; within groups $=16 ;$ total $=19$} \\
\hline$F$ & 11.000 & 52.830 & 7.471 & 50.252 & 4.699 & 25.426 \\
\hline$P$ & & & 0.002 & 0.000 & 0.015 & 0.000 \\
\hline \multicolumn{7}{|c|}{ Calendula officinalis } \\
\hline df & \multicolumn{6}{|c|}{ between groups $=3$; within groups $=16 ;$ total $=19$} \\
\hline$F$ & 4.980 & 36.340 & 2.429 & 22.883 & 1.861 & 4.800 \\
\hline$P$ & 0.013 & 0.000 & 0.103 & 0.000 & 0.177 & 0.014 \\
\hline
\end{tabular}

$F=7.478 ; P=0.000$ ). All main factors (e.g. applied doses) impacting on the mortality level of $S$. granarius were significant at each exposure time with the exception of ventilated textile (VT) covering samples treated with $C$. officinalis for $14 \mathrm{~d}$ and $21 \mathrm{~d}$, which were not significant at $\mathrm{P}<0.05$ (Tables 1 and 2). Furthermore, both covering types (VT, $\mathrm{PN}$ ) were also statistically proven to have an effect on mortality of $S$. granarius.

Insect mortalities are shown in (Fig. 1). As expected, the mortality of insects increased in the treated samples with the duration of the experiment. An increase of insect mortality caused by higher doses of applied herbal oils was evident from $12 \mathrm{~h}$ onward. An increase in the applied doses results in an increase in insect mortality. The changing mortality values show a hyperbolical trend as a function of exposure. Almost complete destruction of experimental insect populations could be observed in the case of $2 \mathrm{ml} \mathrm{kg}^{-1}$ dose until $72 \mathrm{~d}$. Consequently, the highest dose applied yielded insecticidal efficacy within the shortest timeframe for both herbal oils. Mortality was $100 \%$ at $5 \mathrm{ml} \mathrm{kg}^{-1}$ of $H$. rhamnoides $24 \mathrm{~h}$ after the commencement of the treatment, whereas this mortality rate was reached following 12-h exposure to C. officinalis. 


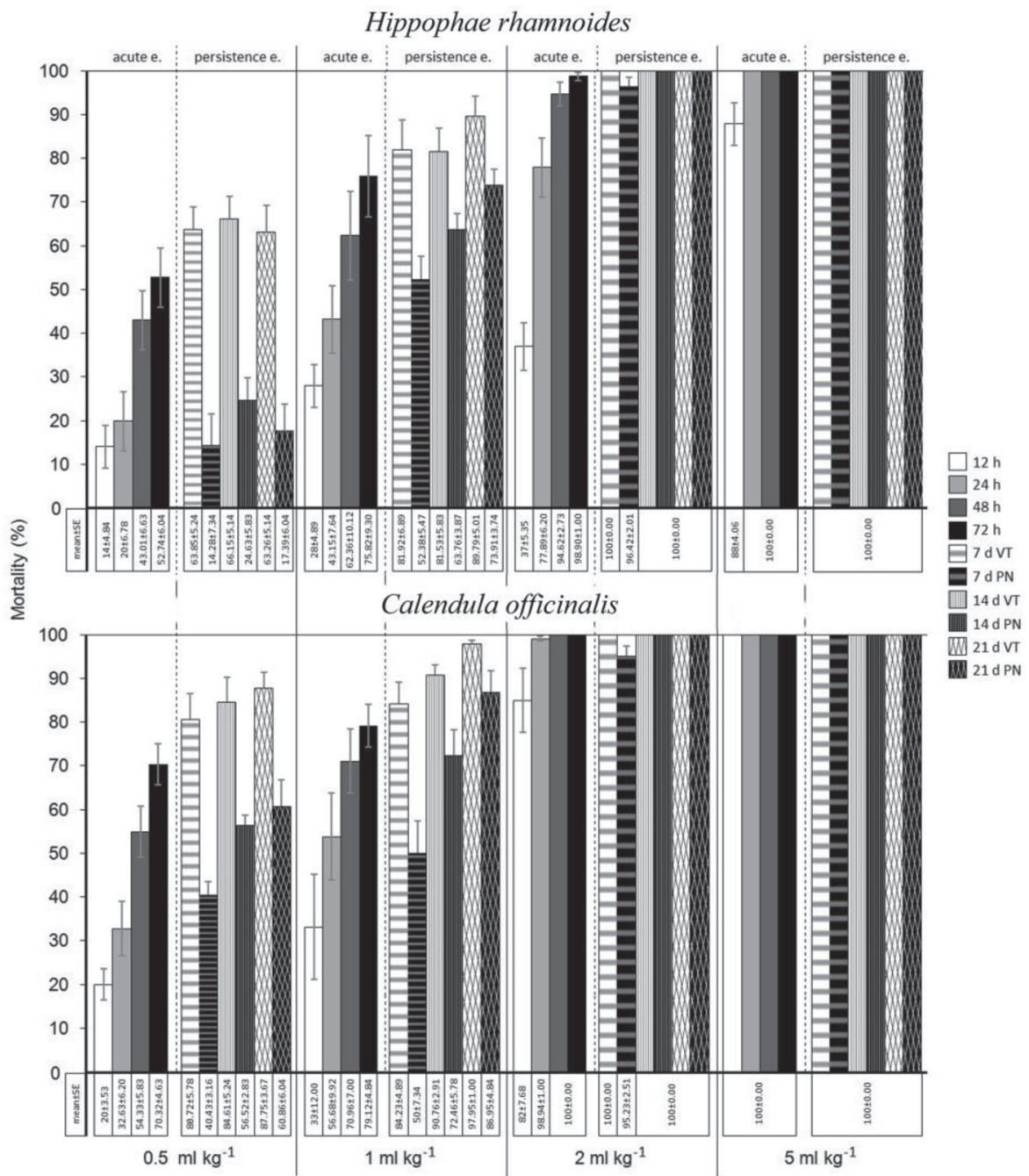

Fig. 1. Calculated mortality (Abbott's correction) of Sitophilus granarius adults (\%) (mean \pm SE) on maize treated with four different dose rates of Hippophae rhamnoides and Calendula officinalis, as a function of exposure times (numbers into the table indicate the calculated Abbott-values and SE). $\mathrm{VT}=$ covered by ventilated textile; $\mathrm{PN}=$ covered by perforated nylon

Acute mortality caused by both examined oils was remarkable. The threshold efficacy (above 90\%) was reached at applying $2 \mathrm{ml} \mathrm{kg}^{-1}$ of $H$. rhamnoides oil after a 48-h exposure time, while for C. officinalis (oil at $2 \mathrm{ml} \mathrm{kg}^{-1}$ ) this period was $24 \mathrm{~h}$. The lower doses were effective after a longer period of exposure time. The acceptable threshold efficacy could not be reached at the lowest dose $\left(0.5 \mathrm{ml} \mathrm{kg}^{-1}\right)$ of both herbal oils at any exposure times. According to the observations on the persistence exposure times $90 \%$ 
average mortality was reached at $1 \mathrm{ml} \mathrm{kg}^{-1}$ dose of $C$. officinalis on the $14^{\text {th }}$ day, while the same dose of $H$. rhamnoides resulted in this level of mortality on the $21^{\text {th }}$ day.

In addition, large differences among average mortality values obtained for the examined herbal oils were demonstrated with regard to the observed insect mortality and treatment efficacy during the implementation of the experiment. These differences were most conspicuous in the case of lower doses $\left(0.5\right.$ and $\left.1 \mathrm{ml} \mathrm{kg}^{-1}\right)$. After a 12-h exposure, a dose of $0.5 \mathrm{ml} \mathrm{kg}^{-1}$ of $C$. officinalis resulted in an average mortality of $20 \%$. In contrast, the same dose of $H$. rhamnoides triggered only $14 \%$ decay in the experimental insect populations. In $C$. officinalis-treated samples the experimental insect mortalities were 1.26-1.63 times higher at doses of $0.5 \mathrm{ml} \mathrm{kg}^{-1}$, and 1.05-1.31 times higher at doses of $1 \mathrm{ml} \mathrm{kg}{ }^{-1}$, respectively, as compared to H. rhamnoides-treated maize exposed for the same period of time (Fig. 1). This discrepancy could not be detected at higher doses yet, due to the high mortality values.

The effect of covering types (VT and PN) of samples on insect mortality was statistically proven for both examined oils (H. rhamnoides: $\mathrm{df}=89 ; F=12.466 ; P=0.001 ; C$. officinalis: $\mathrm{df}=89 ; F=4.395 ; P=0.039)$. Lower insect toxicities were measured in the majority of cases in samples covered by perforated nylon. These conspicuous differences levelled only in the case of complete devastation triggered by higher doses ( 2 and $5 \mathrm{ml} \mathrm{kg}^{-1}$ ).

Progeny production of $S$. granarius and the percentage of dead progeny treated with oils of $H$. rhamnoides and $C$. officinalis can be seen in Table 3 . Progeny numbers of distinct covering types statistically differed from that of intact samples (untreated) (VT: $\mathrm{N}^{\circ}$. progeny $=6.40 \pm 0.50, \%$ dead adults $=13.82 \pm 7.33 ; \mathrm{PN}: \mathrm{N}^{\circ}$. progeny $=30.2 \pm 3.52$, $\%$ dead adults $=5.46 \pm 0.97)(t=0.002)$. The progeny was apparently set back by both herbal oils. In addition, a complete suppression of progeny production was achieved with the highest doses of both oils. However, the increase in the applied oil doses to the adult progeny does not show decrease in the experimental populations. The difference between the effects on progeny of the examined oils could not be proved by Student $t$-probe in any cases. Likewise, in all cases, the effect of oil treatment on the number of dead progeny adults could not statistically be confirmed. At all doses examined, progeny production was higher in samples covered by perforated nylon, but this difference could statistically be confirmed only at 0.5 and $1 \mathrm{ml} \mathrm{kg}^{-1}$ doses of. H. rhamnoides.

\section{Discussion}

Our results are in agreement with several reports that plant extracts may potentially be used to protect stored product against $S$. granarius. However, most of the studies examined the insecticidal effects of these herbal oils when they were air-pulverized or paper-impregnated (Regnault-Roger, 1997; Tunc et al., 2000; Aslan et al., 2004; Calmasur et al., 2006; Kordali et al., 2008; Kotan et al., 2008; Conti et al., 2011; Yildirim et al., 2011; Laznik et al., 2012; Zoubiri and Baaliouamer, 2012).

In this investigation, the herbal oils of $H$. rhamnoides and $C$. officinalis mixed with maize grains were found to be significantly effective against adult and larvae of $S$. granarius. However, the acute and persistence effects of $C$. officinalis were considerably 


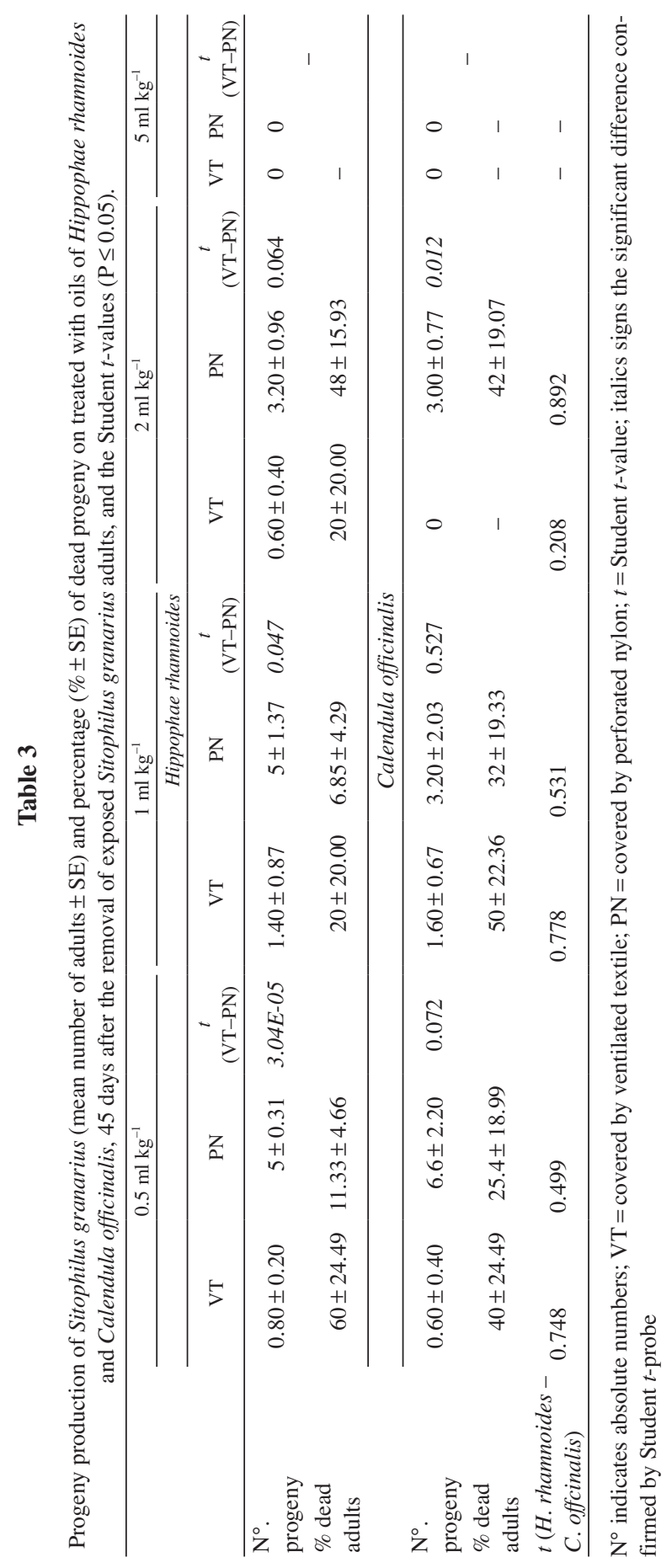


stronger than $H$. rhamnoides. The insecticidal efficacy was substantially higher in $C$. officinalis-treated maize.

The insecticidal effect was influenced by the doses of the herbal oils, exposure times and covering type of treated grain samples. Higher doses and longer exposure time (e.g. Rosmarinus officinalis L.: $7.4 \mu \mathrm{l} / 1$ air, $63 \%$ mortality on $3 \mathrm{~d}$ ) resulted in maximum toxicity on $S$. granarius. Our results reveal, that the quick, acute effects against $S$. granarius can be seen at only high doses $\left(2 \mathrm{ml} \mathrm{kg}^{-1}:\right.$ H. rhamnoides $48 \mathrm{~h}$, C. officinalis $\left.24 \mathrm{~h}\right)$ of the examined plant extracts. Moreover, the lower doses of these herbal oils triggered an acceptable mortality in the persistence period $\left(1 \mathrm{ml} \mathrm{kg}^{-1}: H\right.$. rhamnoides on $21 \mathrm{~d} 89.79 \%$ mortality, C. officinalis on $14 \mathrm{~d} 90.76 \%$ mortality). This result corroborates the findings of some earlier studies (Yildirim et al., 2011; Laznik et al., 2012).

Results of our laboratory test - as compared to those reported in the literature confirm the efficacy-influencing effect of covering type. The higher toxicity in samples covered by perforated nylon can be explained with the obstruction of active compounds volatilization and concomitantly higher temperature. According to Zoubiri and Baaliouamer (2012), mortality was found to increase as a result of an increase in the concentration and the temperature of herbal oils. After a 72-h exposure-time there was a significant difference in mortality between exposures at 25 and $30{ }^{\circ} \mathrm{C}$.

The use of herbal oils as alternatives to control coleopteran insects in stored grains is a sustainable alternative due to the fact that the oils used are derived from natural resources. Such oils could function as a contact toxin, fumigant, repellent, anti-feedant, and oviposition inhibitor (Stefanazzi et al., 2006). Some research has demonstrated that herbal oils have neurotoxic, cytotoxic, phototoxic and mutagenic activities in different organisms (Bakkali et al., 2008). Furthermore, herbal oils act at multiple levels in insects, thus, the possibility of generating resistance is improbable (Faraone et al., 2015). Therefore, it is concluded that herbal oils should be considered as natural alternatives for the control of stored-grain insects.

\section{Acknowledgement}

We are very grateful to Hungarian Government Office of Somogy County, Department of Plant Protection and Soil Conservation for S. granarius cultures.

\section{Literature}

Abbott, W. S. (1925): A method of computing the effectiveness of an insecticide. J. Econ. Entomol. 18, $265-267$. Arthur, F. H. (1996): Grain protectants: current status and prospects for the future. J. Stored Product Research 32, 293-302.

Aslan, I., Özbek, H., Kordali, S., Calmasur, Ö. and Cakir, A. (2004): Toxicity of essential oil vapours obtained from Pistacia spp. to the granary weevil, Sitophilus granarius L. J. Plant Diseases and Protection 111, 400-407.

Bakkali, F., Averbeck, S., Averbeck, D. and Idaomar, M. (2008): Biological effects of essential oils - a review. Food and Chemical Toxicology 46, 446-475. 
Benelli, G., Flamini, G., Canale, A., Molfetta, I., Cioni, P. L. and Conti, B. (2012): Repellence of Hyptis suaveolens whole essential oil and major constituents against adults of the granary weevil Sitophilus granarius. Bulletin of Insectology 65, 177-183.

Calmasur, O., Kordali, S., Kaya, O. and Aslan, I. (2006): Toxicity of essential oil vapours obtained from Achillea spp. to Sitophilus granarius L. and Tribolium confusum (Jacquelin du Val). J. Plant Diseases and Protection 113, 37-41.

Chakraborthy, G. S. (2008): Antimicrobial activity of the leaf extracts of Calendula officinalis (L.). J. Herbal Medicine and Toxicology 2, 65-66.

Chauhan, A. S., Negi, P. S. and Ramteke, R. S. (2007): Antioxidant and antibacterial activities of aqueous extract of sea buckthorn (Hippophae rhamnoides) seeds. Fitoterapia 78, 590-592.

Conti, B., Canale, A., Cioni, P. L., Flamini, G. and Rifici, A. (2011): Hyptis suavolens and Hyptis spicigera essential oils: qualitative analysis, contact toxicity and repellent activity against Sitophilus granarius. J. Pest Science 84, 219-228.

Efstratiou, E., Hussain, A. I., Nigam, P. S., Moore, J. E., Ayub, M. A. and Rao, J. R. (2012): Antimicrobial activity of Calendula officinalis petal extracts against fungi, as well as Gram-negative and Gram-positive clinical pathogens. Complementary Therapies in Clinical Practic 18, 173-176.

Faraone, N., Hillier, N. K. and Cutler, C. (2015): Plant essential oils synergize and antagonize toxicity of different conventional insecticides against Myzus persicae (Hemiptera: Aphididae). PLoS One, 10(5): e0127774. doi: 10.1371/journal.pone.0127774

Fava, A. and Burlando, B. (1995): Influence of female age and grain availability on the ovipositional pattern of the wheat weevil Sitophilus granarius. European J. Entomology 92, 421-425.

Ilboudo, Z., Dabiré, L. C. B., Nébié, R. C. H., Dicko, I. O., Dugravot, S., Cortesero, A. M. and Sanon, A. (2010): Biological activity and persistence of four essential oils towards the main pest of stored cowpeas, Callosobruchus maculatus (F.) (Coleoptera: Bruchidae). J. Stored Products Research 46, 124-128.

Kordali, S., Aslan, I., Çalmaşur, O. and Cakir, A. (2006): Toxicity of essential oils isolated from three Artemisia species and some of their major components to granary weevil, Sitophilus granarius (L.). Industrial Crops Production 23, 162-170.

Kordali, S., Cakir, A., Ozer, H., Cakmakci, R., Kesdek, M. and Mete, E. (2008): Antifungal, phytotoxic and insecticidal properties of essential oil isolated from Turkish Origanum acutidens and its three components, carvacrol, thymol and p-cymene. Bioresource Technology 99, 8788-8795.

Kotan, R., Kordali, S., Cakir, M., Kesdek, Y., Kaya, Y. and Kilic, H. (2008): Antimicrobial and insecticidal activities of essential oil isolated from turkish Salvia hydrangea DC. ex Benth. Biochem. Syst. Ecol. 36, 360-368.

Laznik, Z., Vidrih, M. and Trdan, S. (2012): Efficacy of four essential oils against Sitophilus granarius (L.) adults after short-term exposure. African J. Agricultural Research 7, 3175-3181.

Michel, T., Destandau, E., Le Floch, G., Lucchesi, M. E. and Elfakir, C. (2012): Antimicrobial, antioxidant and phytochemical investigations of sea buckthorn (Hippophae rhamnoides L.) leaf, stem, root and seed. Food Chemistry 131, 754-760.

Obeng-Ofori, D. and Reichmuth, C. H. (1997): Bioactivity of eugenol, a major component of essential oil of Ocimum suave against four species of stored-product Coleoptera. International J. Pest Management 43, 89-94.

Obeng-Ofori, D., Reichmuth, C. H., Bekele, J. and Hassanali, A. (1997): Biological activity of 1, 8 cineole, a major component of essential oil of Ocimum kenyense against stored product beetles. J. Appl. Entomol. 121, 237-243.

Regnault-Roger, C. (1997): The potential of botanical essential oils for insect pest control. Integrated Pest Management Reviews 2, 25-34.

Sarac, A. and Tunc, I. (1995): Residual toxicity and repellency of essential oils to stored-product insects. J. Plant Diseases and Protection 102, 429-434.

Stefanazzi, N., Gutiérrez, M. M., Stadler, T., Bonini, N. A. and Ferrero, A. A. (2006): Actividad biológica del aceite esencial de Tapetes terniflora Kunth (Asteraceae) en Tribolium castaneum Herbst (Insecta, Coleoptera, Tenebrionidae). Boletin de Sanidad Vegetal, Plagas 32, 439-447. 
Stejskal, V. and Kucerova, Z. (1996): The effect of grain size on the biology of Sitophilus granarius L. 1. Oviposition, distribution of eggs and adult emergence. J. Appl. Entomol. 120, 143-146.

Su, H. C. F. (1991): Toxicity and repellency of chenopodium oil to four species of stored-product insect. J. Entomol. Science 26, 178-182.

Tripathi, A. K., Prajapati, V., Gupta, R. and Kumar, S. (1999): Herbal material for the insect pest management in stored grains under tropical conditions. J. Medicinal and Aromatic Plant Sciences 21, 408-430.

Tunc, I., Berger, B. M., Erler, F. and Dagli, F. (2000): Ovicidal of essential oils from five plants against two stored-product insect. J. Stored Product Research 36, 161-168.

Zoubiri, S. and Baaliouamer, A. (2012): GC and GC/MS analysis of the Algerian Lantana camara leaf essential oil: effect against Sitophilus granarius adults. J. Saudi Chemical Society 16, 291-297.

Yildirim, E., Kordali, S. and Yazici, G. (2011): Insecticidal effects of essential oils of eleven plant species from Lamiaceae on Sitophilus granarius. Romanian Biotechnology Letters 16, 6703-6709. 